\title{
Carbon markets and technological innovation
}

\author{
Thomas A. Weber ${ }^{\mathrm{a}, *}$, Karsten Neuhoff ${ }^{\mathrm{b}}$ \\ a Department of Management Science and Engineering, Stanford University, Stanford, CA 94305-4026, USA \\ ${ }^{\mathrm{b}}$ German Institute for Economic Research (DIW Berlin), 10117 Berlin, Germany
}

\section{A R T I C L E I N F O}

\section{Article history:}

Received 22 June 2009

Available online 10 June 2010

\section{Keywords:}

Carbon emissions

Carbon taxes

Cap-and-trade

Environmental regulation

Induced technological innovation

Price caps

Price floors

Prices vs. quantities

\begin{abstract}
A B S T R A C T
This paper examines the effects of firm-level innovation in carbon-abatement technologies on optimal cap-and-trade schemes with and without price controls. We characterize optimal cap-and-trade regulation with a price cap and a price floor, and compare it to the special cases of pure taxation and a simple emissions cap. Innovation shifts the tradeoff between price- and quantity-based instruments towards quantitybased emissions trading schemes. More specifically, an increase in innovation effectiveness lowers the optimal emissions cap, and leads to relaxed price controls unless the slope of the marginal environmental damage curve is small. Because of the decrease in the emissions cap, innovation in abatement technologies can lead to a higher expected carbon price, so as to provide sufficient incentives for private R\&D investments. The expected carbon price decreases once innovative technologies are widely used.
\end{abstract}

(c) 2010 Elsevier Inc. All rights reserved.

\section{Introduction}

In order to limit global warming, the Intergovernmental Panel on Climate Change (IPCC) noted that worldwide annual carbon emissions need to be cut approximately in half by 2050 [24]. A mix of different policy instruments is likely to be required to deliver the necessary emissions reductions, including a price for carbon, incentives for technological innovation, and suitable administrative procedures [55]. We focus on the first two by exploring the impact of price- and quantity-control instruments on both emissions-abatement efforts and private investment in the improvement of abatement technologies. For this, we construct optimal cap-and-trade schemes with price controls (of which pure taxation and standard cap-and-trade are special cases) and examine how a change in innovation effectiveness influences the design of policy instruments. We find that an increase in innovation effectiveness can, somewhat counter-intuitively, lead to higher carbon prices. This stems from the fact that in order to encourage technological innovation, the welfare-maximizing regulator may choose to aggressively decrease the emissions cap, leading to a higher expected carbon price despite the anticipated decrease in abatement cost. Because of an increase in carbon-price volatility from an emissions cap, which encourages innovation, a higher innovation effectiveness favors quantity-based instruments over price-based instruments. In the case of hybrid schemes, an increased innovation effectiveness leads to looser price controls (i.e., lower price floor and higher price cap), unless the slope of the marginal environmental damage curve is small, in which case an inverse result obtains.

There are three main reasons for a simultaneous consideration of several regulatory instruments. ${ }^{1}$ First, a joint optimization of several instruments (prices and quantities) cannot do worse than optimizing any policy instrument individually [49,61].

\footnotetext{
* Corresponding author. Fax: +16507231614.

E-mail addresses: webert@stanford.edu (T.A. Weber), kneuhoff@diw.de (K. Neuhoff).

1 There are also reasons against hybrid cap-and-trade markets, such as the increased design complexity, commitment problems, political influence activities (e.g., price controls are subject to significant lobbying activities, as are already the number of emissions permits as well as the mode of the initial permit allocation), and increased risk of incompatibilities of different designs across countries (cf. Section 4$)$.
} 
Second, analysis focusing on economic impacts (abstracting from the political economy of implementation) shows that no single policy instrument clearly dominates the others [14,41,53]. Third, the regulatory policy needs to influence multiple decisions, in our case, the capital investment in innovation as well as the decision about emissions (output) [12,25,33]. In terms of results, we characterize the optimal policy, a cap-and-trade scheme with price controls (in the form of price cap and price floor), and contrast it to the classical schemes of pure taxation and cap-and-trade without price controls, with respect to performance and the firms' incentives to abate and innovate. Tight price controls limit the firms' exposure to risk on the market. On the other hand, they tend to increase the variability of aggregate emissions, thus augmenting the volatility of environmental damages. This in turn leads to higher expected damages, as long as the damage function is convex in aggregate emissions. While the firms' innovation becomes more effective, it is always optimal to set a more ambitious, lower emissions cap; optimal price controls tighten only when the slope of the marginal environmental damage curve (per unit of emissions) is small. When the slope of marginal environmental damages is large, then it is best for a regulator to relax price controls (i.e., drop the price floor and raise the price cap) in response to an increase in the firms' innovation effectiveness. While at first glance this appears to be a contradiction to Weitzman's [60] seminal analysis of 'prices vs. quantities,' which predicts-in the absence of innovation-less stringent price controls as a consequence of an increase in marginal environmental damages, the same tradeoff prevails at any fixed level of innovation effectiveness. This, together with the fact that price controls are relaxed when innovation effectiveness increases and environmental damages are large, implies that the sensitivity of the price controls to the general carbon-price level increases substantially as innovation effectiveness increases. The heightened sensitivity underlines the necessity to consider all available instruments and relevant effects jointly, as welfare losses are compounded in the presence of additional uncertainty about macroeconomic conditions, innovation costs, or environmental damages.

In the scientific community, a consensus has emerged that climate change and carbon emissions from man's economic activity are intertwined, and that they need to be addressed simultaneously [40]. The economic activity considered here includes two decisions taken by firms: first, how much carbon (dioxide) to emit ('emissions control'), and, second, how much to invest in improving carbon-abatement technologies ('technological innovation').

Emissions control: A Pigouvian tax [47] corrects a distortion generated by the lack of a price for the expected environmental damages through carbon (or 'carbon-equivalent') emissions [44], unlike many other modes of input taxation which lead to deadweight losses [1]. An alternative course of action for governments, initially suggested by Coase, is to issue tradable emissions permits [5-7,36]. Such quantity-based regulation is sometimes viewed as inferior on the grounds of significant transaction costs [53], given that an administrative system for levying tax is usually available. In the absence of transaction-cost considerations, the optimal choice between tax or quantity-based allowance-trading scheme depends on the nature of the uncertainty [60], ${ }^{2}$ since environmental damages are typically modelled as a convex function of aggregate emissions, an increase in risk [50] increases expected damages (as a consequence of Jensen's inequality), which in turn favors quantity-based regulation. If, on the other hand, the loss in society's payoffs due to uncertainty in emissions and resulting expected environmental damages are small compared to the loss due to randomness in market prices, then an emissions tax is preferred, as it eliminates price uncertainty. Naturally, as Weitzman [61] shows, a combination of price and quantity regulation cannot do worse than either policy instrument alone. In Weitzman's treatment a price-quota system determines a socially optimal reward as a function of its emissions for each participating firm. In real-world settings, it is impossible to implement such infinite-dimensional policies (in the form of reward functions) using simple cap-and-trade. Yet, a first approximation, which still combines the features of pure taxation and a simple cap-and-trade system, is a market for emissions allowances with price controls: an emissions cap controls total emissions and determines the initial number of permits to be issued. As long as the resulting market price for emissions is within pre-specified price bounds, this results in a normal cap-and-trade system. If the carbon price reaches the prespecified maximum price (price cap), additional permits are issued $[30,48,49])$. The price floor can be implemented with a reservation price for allowance auctions [18], by governments issuing option contracts on the carbon price as a commitment to buy back permits when the carbon price drops below the price floor. More recently, Philibert [46] uses extensive Monte-Carlo simulations to study the effect of price caps and price floors on climate policy. The simulation results confirm that price controls, while increasing expected environmental damage, dampen expected aggregate abatement costs. To this we add a simplified formal framework and an analysis of the interaction with innovation.

Technological innovation: The introduction of a carbon price via incentive-based emissions-control policies is, according to Hicks' ([19], p. 132) 'induced invention hypothesis,' likely to affect the rate and path of technological change. This hypothesis sparked not only a stream of research attempting to formally establish this effect in general-equilibrium models [26,59], but also several severe criticisms related to the description of knowledge accumulation [39,51], producing a hiatus of results. Recent surveys on technological change in economic models of environmental policy emphasize the need to consider innovation as an endogenous decision variable rather than an exogenous process [9,29]. Milliman and Prince [33] consider three phases of technological change: innovation, diffusion, and agency response. They find that either a tax or a system with auctioned carbon permits dominates regimes with free permits or imposed technological standards in view of promoting technological change at the firm level. Building on this work, Jung et al. [25] obtain similar findings at the industry level; in particular, they show that firm-specific standards are dominated by quantity-based policy

\footnotetext{
${ }^{2}$ Various generalizations of Weitzman's [60] analysis have been proposed, such as for situations with asymmetric information between regulator and firms [21,27], correlated uncertainty [54], hybrid price-quantity controls [49,61], incomplete enforcement [35], and bankable permits [11].
} 
instruments because the latter yields not only a lower marginal cost of abatement, but also additional savings due to a reduced market price for carbon. ${ }^{3}$ As most of the subsequent literature, we therefore restrict our attention to incentivebased policy instruments. Using a model with a linear environmental damage function and in the absence of uncertainty or firm heterogeneity, Parry [42] finds that tax and (either free or auctioned) emissions permits have similar efficiency properties. ${ }^{4}$ Parry points out that 'R\&D efficiency gains' may arise because firms fail to take into account the positive externalities associated with technology spillover and environmental-damage reduction. With a convex environmental damage cost function but in the absence of uncertainty, Denicolò [8] demonstrates that, without commitment, taxes and cap-and-trade result in the same carbon price with identical welfare properties and incentives to innovate (for a single innovation leader), whereas, with commitment, taxes provide better marginal incentives for innovation and dominate in terms of welfare. In a similar setting, Fischer et al. [12] show that when the spillover effect is large (decreasing the appropriability of innovation) auctioned permits lead to higher welfare gains than taxes. Yet, Fischer et al. note that neither instrument clearly dominates the other, which highlights the potential benefits from combining price-based and quantitybased regulation in a cap-and-trade regime with price controls. In the terminology of these earlier studies, our model concentrates on innovation as the first phase of technological change, with spillover effects (i.e., the second phase) in our model being isomorphic to a shift in innovation effectiveness. The agency response (i.e., the third phase) to innovation is restricted to the first period where the regulator commits to a certain regulatory regime. ${ }^{5}$ Our model extends earlier work in several ways: first, it allows for macroeconomic uncertainty, preserving the Weitzman tradeoff between prices and quantities. Second, it incorporates both quantity-based and price-based instruments, which leads to optimality of a hybrid scheme. Third, it features ex-ante firm heterogeneity in the ability to abate carbon. In our model, we assume that there is a continuous set of different technologies without technology spillover.

\section{The model}

We consider a unit mass of firms, indexed by $\theta \in \Theta \subset \mathbb{R}_{++}$, and distributed on the (measurable) type space $\Theta$ with the cumulative distribution function (cdf) $F: \Theta \rightarrow[0,1]$, so that the mean

$$
\mu=\int_{\Theta} \theta d F(\theta)
$$

and the variance

$$
\sigma_{\theta}^{2}=\int_{\Theta}(\theta-\mu)^{2} d F(\theta)
$$

both exist and are finite. The model timing consists of three time periods (stages), indexed by $t \in\{0,1,2\}$. At time $t=0$ (regulation stage), a regulator commits to a regulatory policy $R=(E, L, U)$ by announcing an emissions cap $E$, a price floor $L$, and a price cap $U$. In particular, the regulator may choose pure taxation or a cap-and-trade scheme without price controls. ${ }^{6}$ At time $t=1$ (innovation stage), any firm has the option to invest in innovation, which may reduce its cost of carbon abatement in the future. Finally, at time $t=2$ (implementation stage), each firm $\theta \in \Theta$ chooses its carbon emissions level. We now describe each of the three stages in detail, starting with the last.

Implementation stage $(t=2)$ : Without any price on carbon or other output restrictions, firm $\theta$ expects to produce its business-as-usual (BAU) carbon emissions of $e_{0}(\theta)$. The actual BAU carbon emissions for firm $\theta$ are subject to a macroeconomic random shock $\tilde{\varepsilon}$. The latter is common to all firms and has cdf $G: \mathbb{R} \rightarrow[0,1]$, with $E \tilde{\varepsilon}=0$ and $0<E \tilde{\varepsilon}^{2}=\sigma_{\varepsilon}^{2}<\infty .^{7}$ Given a realized BAU carbon emissions level $\hat{e}_{0}=e_{0}(\theta)+\varepsilon$, firm $\theta$ 's cost of abating its carbon emissions to a level $e \leq \hat{e}_{0}$ is

$$
C\left(e, \hat{\rho} \theta \mid \hat{e}_{0}\right)=\frac{\left(\hat{e}_{0}-e\right)^{2}}{2 \hat{\rho} \theta},
$$

where $\hat{\rho} \geq 1$ denotes the outcome of the firm's investment in the preceding innovation stage, further detailed below. All else being equal, the larger the firm's type $\theta$, the smaller its marginal abatement cost $\left(\hat{e}_{0}-e\right) /(\hat{\rho} \theta)$. ${ }^{8}$ Given a price $p$ for each

\footnotetext{
${ }^{3}$ Fischer et al. [12] call these two principal sources of private gains from innovation the 'abatement cost effect' and the 'emissions payment effect,' respectively.

${ }^{4}$ In our model we assume that $\mathrm{CO}_{2}$ allowances are auctioned off and therefore that firms bear the full cost of a carbon price. For example, this is the current objective of the EU emissions trading scheme. If free allocation reduces firms' cost of allowances, it also reduces the incentives to innovate [33]. Administrative procedures associated with the detailed allocation provisions can further distort incentives for innovation [16].

${ }^{5}$ For example, in terms of agency response, Goulder and Mathai [13] show that induced technological change leads to a lower carbon tax.

6 In Section 3, these important special cases are examined separately.

7 It is possible to allow for independent firm-specific (idiosyncratic) zero-mean random shocks $\tilde{\varepsilon}(\theta)$ with finite variances satisfying a Lindeberg condition, which complicates the presentation and, via the central limit theorem, leads to an equivalent result.

8 The affine form of the marginal abatement cost is chosen as in [61], so as to obtain explicit model results. More generally, marginal abatement costs are convex and decrease to zero as the emissions level approaches the firm's BAU level [34]. Enkvist et al. [10] use data to find an approximately affine marginal abatement-cost curve. They also note that marginal abatement cost may become negative for small levels of abatement, as small emissions improvements could be implemented at a gain to a firm. In our model we assume that all such gains have been internalized, so that the marginal abatement cost at the firm's realized BAU emissions level vanishes.
} 
unit of carbon emissions (typically measured in $\mathrm{tCO}_{2} \mathrm{eq}$, i.e., tons of 'carbon-dioxide equivalent, ${ }^{, 9}$ and here denoted by tCO for simplicity), the firm's total cost of producing at the emissions level $e$ is

$$
T C\left(e, p, \hat{\rho} \theta \mid \hat{e}_{0}\right)=C\left(e, \hat{\rho} \theta \mid \hat{e}_{0}\right)+p e .
$$

The firm's optimal emissions minimize its total cost, and is uniquely determined by ${ }^{10}$

$$
e^{*}\left(p, \hat{\rho} \theta \mid \hat{e}_{0}\right)=\hat{e}_{0}-\hat{\rho} \theta p .
$$

At this output level, the firm's optimal total carbon emissions cost is

$$
T C^{*}\left(p, \hat{\rho} \theta \mid \hat{e}_{0}\right)=\hat{e}_{0} p-\frac{\hat{\rho} \theta p^{2}}{2} .
$$

Innovation stage $(t=1)$ : Given the announcement of a carbon pricing policy, each firm $\theta$ chooses the level $y$ of innovative activity. The cost of pursuing the innovative activity $K(y)$ is known, but the outcome of the innovation $\tilde{\rho}(y)$ is uncertain. The innovation provides an advantage over the existing technology if and only if $\tilde{\rho}(y)>1$. Only in this case will it be utilized. We assume that the expected outcome of innovation for a certain level of innovative activity $y$ is ${ }^{11}$

$$
y=\mathbb{E}[\max \{\tilde{\rho}(y), 1\} \mid y]-1 \geq 0 .
$$

Firm $\theta$ 's expected net payoff from innovating is

$$
\pi(p, y, \theta)=\frac{\theta y p^{2}}{2}-K(y)
$$

Assuming that $K(y)$ is a continuously differentiable, convex, and increasing function (satisfying the Inada conditions $K(0)=K^{\prime}(0)=0$ and $\left.K^{\prime}(\infty)=\infty\right)$, the optimal innovation is determined by the first-order optimality condition $\theta p^{2} / 2=K^{\prime}(y)$. If we assume, for the sake of discussion, that

$$
K(y)=c y^{2} / 2,
$$

where $c$ is a positive constant, firm $\theta$ 's optimal innovation becomes

$$
y^{*}(p, \theta)=\frac{\theta p^{2}}{2 c},
$$

resulting in an expected net payoff of

$$
\pi^{*}(p, \theta)=\frac{\theta^{2} p^{4}}{8 c}
$$

Thus, the benefits of improving abatement technologies are highly sensitive to the carbon price. Nonetheless, the expected payoff of optimal innovation is positive, as long as small improvements are cheap ( $\left.\operatorname{since} K^{\prime}(0)=0\right){ }^{12}$

Regulation stage $(t=0)$ : The regulator commits to a (deterministic) regulatory policy

$$
R=(E, L, U)
$$

consisting of an emissions cap $E$ (implemented by issuing a set quantity of emissions permits), and a price interval [ $L, U]$ for the secondary market in emissions permits. In the event the market price $p$ reaches the price floor $L$, the regulator offers firms to buy back emissions permits at the price $L$. If the market price $p$ reaches the price cap $U$, the regulator offers firms additional permits at the price $U$.

Remark 1. (i) A pure carbon tax $\tau$ can be implemented by choosing $R=(E, \tau, \tau)$, where $E \geq 0$ is arbitrary, since the carbon market is bypassed by the regulator, who offers an ex-ante unlimited number of carbon emissions permits at the fixed price of $\tau$. (ii) A pure carbon emissions cap of $E$ is also a special case, which can be implemented by setting $R=(E, 0, \infty)$, effectively disabling the price controls with $L=0$ and $U=\infty$.

The set of feasible regulatory policies is

$$
\mathcal{R}=\left\{(E, L, U) \in \mathbb{R}_{+}^{3}: L \leq U\right\} .
$$

\footnotetext{
${ }^{9}$ One ton of carbon-dioxide equivalent (denoted by $\mathrm{tCO}_{2} \mathrm{eq}$ ) is the weight of a greenhouse gas which would have the same time-integrated radiative forcing (over a period of 100 years) as one ton of $\mathrm{CO}_{2}$.

${ }^{10}$ In principle it is possible to obtain negative values for optimal carbon emissions, which implies that the firm would substitute its production further away from carbon than its zero-carbon emissions normalization would indicate. Alternatively, the firm can accumulate carbon credits. The unconstrained optimization also simplifies the model in that the expected level of aggregate emissions with macroeconomic uncertainty corresponds to the aggregate emissions level in the absence of this uncertainty ('certainty equivalence'). Relaxing this condition would impact modelling results only marginally, and would also raise the additional question of the precise measurement of the absolute level of BAU emissions.

${ }^{11}$ This is without any loss in generality, as for any arbitrary parametrization of the innovative process $\tilde{\rho}(x)$ in terms of $x$, one can simply set $y$ equal to $v(x) \equiv \mathbb{E}[\max \{\tilde{\rho}(x), 1\} \mid x]-1$ and then reparametrize the innovative process in terms of $\hat{x}=\left(\hat{x}_{0}, x\right)$ which contains $\hat{x}_{0}=y=v(x)$ as one component.

${ }^{12}$ Enkvist et al. [10] argue that the cost of abating the first units of carbon emissions, net of benefits, may on average be negative. The assumption that $K^{\prime}(0)=0$ implies that any firm's BAU emissions are set to the level at which it has internalized any such abatement benefits.
} 
To formulate the regulator's problem, we first aggregate the firms' expected emissions at a given carbon price $p$, which yields (using Eqs. (2)-(4)) the expected aggregate carbon emissions

$$
Q(p, \varepsilon)=\int_{\Theta} e^{*}\left(p,\left(1+y^{*}(p, \theta)\right) \theta \mid e_{0}(\theta)+\varepsilon\right) d F(\theta)=e_{0}+\varepsilon-\mu p-\frac{\mu^{2}+\sigma_{\theta}^{2}}{2 c} p^{3},
$$

where we denote by

$$
e_{0}=\int_{\Theta} e_{0}(\theta) d F(\theta)
$$

the expected aggregate BAU emissions in the economy. To understand the integral in Eq. (6), note first that by Eq. (3) a firm of cost type $\theta$, when investing in technology at the optimal innovation level $y^{*}(p, \theta)$, expects to transition to the improved cost type $\hat{\theta}=\left(1+y^{*}(p, \theta)\right) \theta$. Substituting Eqs. (2) and (4) in the integrand, the right-hand side of Eq. (6) obtains via straightforward integration. To clarify the influence of innovation, aggregate emissions can be rewritten in the form

$$
Q(p, \varepsilon)=e_{0}+\varepsilon-\mu p\left(1+\beta p^{2}\right),
$$

where, with $\kappa=\sigma_{\theta} / \mu$ as the coefficient of variation of the cost-type distribution,

$$
\beta=\frac{\mu^{2}+\sigma_{\theta}^{2}}{2 \mu c}=\frac{\mu}{2 c}\left(1+\kappa^{2}\right)
$$

denotes the (aggregate) innovation effectiveness. ${ }^{13}$ It is possible to understand the definition of the innovation effectiveness $\beta$ starting from Eq. (7). For this, let $Q_{0}$ denote the aggregate emissions in the absence of innovation (i.e., when $c \rightarrow \infty$ or, equivalently, $\beta=0)$. Further, let $A_{0}=\mu p$ be the abatement without innovation $(\beta=0)$, and $A=A_{0}+A_{I}$ be the abatement with innovation $(\beta>0)$. Then from Eq. (7) we obtain that

$$
\frac{Q_{0}-Q}{A_{0}}=\frac{e_{0}-A_{0}-\left(e_{0}-A_{0}-A_{I}\right)}{A_{0}}=\frac{A_{I}}{A_{0}}=\beta p^{2},
$$

where $e_{0}$ is the business-as-usual aggregate emissions level. Thus, the innovation effectiveness,

$$
\beta=\frac{1}{p^{2}} \frac{A_{I}}{A_{0}}
$$

is for a given carbon price $p$ (e.g., fixed to a tax) proportional to the ratio of the abatement increment from innovation, $A_{I}$, to the default abatement, $A_{0}$. The fact that $\beta$ is normalized by the price takes into account the firms' motivation to innovate, which is proportional to $p^{2}$ as in Eq. (4).

Remark 2. Two aspects of the information structure are important in standard models of innovation: private information and information transmission via spillover or licensing. In some models, such as [8], there is a single innovating firm which can extract rent from the other firms ex post. The fact that in our model the firms are continuously distributed limits the market power each firm has. No firm can discretely benefit at the expense of other firms using private information. Second, we do not consider spillover in our model explicitly, as it can be effectively incorporated by suitable pre-conditioning of the cost-type distribution (each firm can expect a certain increment in its cost type, depending on the firms' investment in innovation). Thus, whatever the precise nature of the spillover (e.g., in a regime with partial appropriability as in [12]), the presence of spillover in our model would correspond to an increase of the innovation effectiveness $\beta .^{14}$

Remark 3. If $\mu$ and $\kappa$ (or $\sigma_{\theta}$ ) are fixed, then the innovation effectiveness is proportional to $1 / c$, and can therefore be viewed as a parameter that describes the cost of innovation. But the overall effectiveness of innovation to influence aggregate emissions depends on the cost-type distribution. As is evident from Eq. (8), innovation effectiveness increases both in the mean $\mu$ and in the coefficient of variation $\kappa$. If $c$ increases by a factor of $\alpha>1$, the innovation effectiveness decreases by a factor of $\alpha$, all else equal. Yet, if at the same time the average cost type $\mu$ also increases by a factor of $\alpha$ due to an outside shock that is not connected to the firms' own innovative activity (but, e.g., to a direct technology transfer), then the decrease in $c$ and the decrease in $\mu$ cancel each other, and $\beta$ remains unchanged: the effectiveness of innovation depends only on the ratio of $\mu$ and $c$. A given cost $c$ is less effective for innovation if firms are on average more efficient (i.e., their cost-type expectation goes up). A similar intuition applies when $\mu$ stays constant, and the coefficient of variation $\kappa$ increases from zero to $\sqrt{\alpha}-1>0$. The resulting mean-preserving spread in the cost-type distribution increases the benefits of a unit of innovation in the aggregate, for a fixed carbon price. ${ }^{15}$

\footnotetext{
${ }^{13}$ For $\mu>0$, the relation between $(\mu, \kappa)$ and $\left(\mu, \sigma_{\theta}\right)$ is one-to-one, so that they are interchangeable.

${ }^{14}$ Of course, this change in $\beta$ would be endogenous, as for example with zero investment no innovation spillovers could be expected, so that $\beta$ remains unchanged. Endogenizing $\beta$ would certainly make the model more complex, but not change the general insights obtained in the presence of any positive $\beta$.

${ }^{15}$ The expectation of the firms' expected profit, which is convex in $\theta$ for a given carbon price $p$ (cf. Eq. 5), increases when the cost-type distribution is shifted to a second-order stochastically dominated distribution of the same mean [50].
} 
At the aggregate emissions level $Q$ environmental damages are given by

$$
D(Q)=\frac{d Q^{2}}{2},
$$

where $d$ denotes the slope of the marginal environmental damage curve. ${ }^{16}$ The expected environmental damages are therefore

$$
\bar{D}(R)=\mathbb{E}[D(Q(\tilde{p}, \tilde{\varepsilon})) \mid H(\tilde{p}, \tilde{\varepsilon}, R)=0],
$$

where the measure of the stochastic price $\tilde{p}$ is determined by the market-clearing condition ${ }^{17}$

$$
H(p, \varepsilon, R) \equiv(U-p)(p-L)(E-Q(p, \varepsilon))=0 .
$$

Insofar as the regulatory policy $R$ influences aggregate emissions, it also controls the level of expected environmental damages. The expected aggregate cost of carbon abatement with the policy $R$ is

$$
\bar{C}(R)=\mathbb{E}\left[C\left(e^{*}\left(\tilde{p},\left(1+y^{*}(\tilde{p}, \tilde{\theta})\right) \tilde{\theta} \mid e_{0}+\tilde{\varepsilon}\right),\left(1+y^{*}(\tilde{p}, \tilde{\theta})\right) \tilde{\theta} \mid e_{0}+\tilde{\varepsilon}\right) \mid H(\tilde{p}, \tilde{\varepsilon}, R)=0\right],
$$

where the optimal emissions $e^{*}$ are given in Eq. (2) and optimal innovation is determined by Eq. (4). The firms' expected aggregate social cost of innovation $\bar{K}(R)$ of the policy $R$ is

$$
\bar{K}(R)=\lambda \mathbb{E}\left[K\left(y^{*}(\tilde{p}, \tilde{\theta})\right) \mid H(\tilde{p}, \tilde{\varepsilon}, R)=0\right],
$$

where the constant $\lambda \in[0,1]$ describes how much society (i.e., the regulator) cares about these costs. The reason why one would expect generally that $\lambda<1$ is that firms are able to appropriate a portion of the innovation payoffs in the form of intellectual property rights (on top of the abatement-cost savings), resulting in private benefits, e.g., through international technology licensing or savings in future unmodelled periods, that offset the innovation cost to society at least in part. ${ }^{18}$

The regulatory problem: An optimal regulatory policy $R^{*}$ maximizes expected welfare $\bar{W}(R)$ (or, equivalently, minimizes total expected social cost $S C(R) \equiv-\bar{W}(R)$ ),

$$
\bar{W}(R)=-\bar{C}(R)-\bar{D}(R)-\bar{K}(R),
$$

i.e., it is such that

$$
R^{*} \in \underset{R \in \mathcal{R}}{\operatorname{argmax}} \bar{W}(R) .
$$

\section{Optimal regulation}

Common regulatory schemes include pure carbon taxation, cap-and-trade markets without price controls, and cap-andtrade markets with price controls as a generalization which includes the first two. Here we examine all three regulatory schemes. In doing this, we parametrize the firms' innovation effectiveness by $\beta \geq 0$ and examine the effect of innovation as $\beta$ increases, in particular over the 'base case' without innovation (when $\beta=0$ ). Such increases could come about exogenously as a result of government sponsorship, or endogenously through 'learning by doing' with private investment in R\&D, which tends to generate further technological possibilities [15].

To compute the regulator's objective function (expected total welfare $\bar{W}$ ), we first determine the price $p(\varepsilon, R)$ of carbon using the market-clearing condition (10) as a function of the macroeconomic shock $\varepsilon$ and the regulatory policy $R=(E, L, U)$, which yields

$$
p(\varepsilon, R)= \begin{cases}U & \text { if } \varepsilon \geq \bar{\varepsilon}(E, U), \\ L & \text { if } \varepsilon \leq \underline{\varepsilon}(E, L), \\ \eta p_{0}(\varepsilon, E) & \text { otherwise, }\end{cases}
$$

where

$$
p_{0}(\varepsilon, E)=\left(e_{0}+\varepsilon-E\right) / \mu
$$

is the market price for carbon without innovation, and

$$
\begin{aligned}
& \bar{\varepsilon}(E, U)=\mu U\left(1+\beta U^{2}\right)-\left(e_{0}-E\right), \\
& \underline{\varepsilon}(E, L)=\mu L\left(1+\beta L^{2}\right)-\left(e_{0}-E\right)
\end{aligned}
$$

\footnotetext{
${ }^{16}$ A quadratic form for environmental damages in terms of pollution stocks (here: $\mathrm{CO}_{2}$ concentration) is widely used in the literature [2,21]. In our model, there is only a single emissions period, such that for the purposes of determining the medium to long-term impact of regulation in moving the emissions path, we use a quadratic damage function in emissions. Tol [57] provides additional justification for why a quadratic form is useful in practice.

${ }^{17}$ For the measure of $\tilde{p}$ to be determined by the condition $H(\tilde{p}, \tilde{\varepsilon}, R)=0$ it is, by the inverse function theorem, enough to assume that $\partial H(p, \varepsilon, R) / \partial p$ exists and is nonzero almost everywhere.

${ }^{18}$ In addition, society may be able to obtain a 'double dividend' from the revenues generated by the sale of the carbon permits [3,4]. For simplicity, we assume that the double dividend is zero.
} 
are the upper and lower thresholds for BAU emissions realizations that trigger price controls. The perturbation term in Eq. (14),

$$
\eta=3\left(1+A+\frac{1}{A}\right)^{-1} \in(0,1]
$$

with $A=\left(1+(27 b / 2)+\frac{3}{2} \sqrt{12 b+81 b^{2}}\right)^{1 / 3}$ and $b=\beta p_{0}^{2}$, is decreasing in the innovation effectiveness $\beta$. When innovation becomes prohibitively expensive (so that $c \rightarrow \infty$ ), then $\beta$ (or, equivalently, $b$ ) vanishes and consequently $\eta=1$.

Remark 4. It is possible to provide a simple a-priori estimate of the impact of innovation effectiveness on the market price for carbon and the firms' optimal innovation. From Eqs. (7), (10), and (15) we obtain that $p_{0}=p\left(1+\beta p^{2}\right)$, which is equivalent to $\xi^{3}-\xi^{2}=\beta p_{0}^{2}$, where $\xi=p_{0} / p \geq 1$ is the ratio of the market prices without innovation (for $\beta=0$ ) to those with innovation (for $\beta>0$ ). Since $\xi-1 \leq \xi^{3}-\xi^{2} \leq \xi^{3}-1$ for all $\xi \geq 1$, we have

$$
\frac{1}{1+\beta p_{0}^{2}} \leq \frac{p}{p_{0}} \leq \frac{1}{\sqrt[3]{1+\beta p_{0}^{2}}} \leq 1
$$

for all $\beta \geq 0$. For example, when $\beta p_{0}^{2}=7$, the carbon price with innovation is between $1 / 8$ and $1 / 2$ of the carbon price without innovation. As $\beta \rightarrow \infty$, the relative price impact approaches $100 \%$. Relation (19) together with the market-clearing condition (as formulated in Eq. (23) below) also bounds the impact of innovation effectiveness on the optimal innovation $y^{*}$ in Eq. (4),

$$
\frac{\sqrt{1+\beta p_{0}^{2}}-1}{1+\kappa^{2}} \leq y^{*} \leq \frac{\beta p_{0}^{2}}{1+\kappa^{2}},
$$

where $\kappa$ is the coefficient of variation in Eq. (8).

The expected social welfare $\bar{W}$ as a function of $R$ in Eq. (13) is obtained by substituting the market price $p(\varepsilon, R)$ in Eqs. (9), (11), and (12), leading to

$$
\begin{aligned}
& \bar{C}(R)=\frac{\mu}{2} \int_{-\infty}^{\infty}\left(1+\beta p^{2}(\varepsilon, R)\right) p^{2}(\varepsilon, R) d G(\varepsilon), \\
& \bar{D}(R)=\frac{d}{2} \int_{-\infty}^{\infty}\left(e_{0}+\varepsilon-\mu p(\varepsilon, R)\left(1+\beta p^{2}(\varepsilon, R)\right)\right)^{2} d G(\varepsilon), \\
& \bar{K}(R)=\frac{\lambda \mu}{4} \int_{-\infty}^{\infty} \beta p^{4}(\varepsilon, R) d G(\varepsilon) .
\end{aligned}
$$

\subsection{Pure taxation}

Consider first a restriction of feasible policies to impose a carbon tax $\tau \geq 0$, which is equivalent to making an unlimited amount of allowances available at a fixed price $L=U=\tau$. In that case, $R=(\infty, \tau, \tau)$ and $p(\varepsilon, R) \equiv \tau$.

Proposition 1 (Optimal tax). For any $\beta \geq 0$, let $\tau^{*}(\beta)$ be the optimal carbon tax.

(i) In the absence of innovation, i.e., when $\beta=0$, the optimal tax is

$$
\tau^{*}(0)=\frac{d e_{0}}{1+\mu d} \equiv \tau_{0}^{*}
$$

(ii) The optimal tax $\tau^{*}(\beta)$ decreases (in a neighborhood of $\beta>0$ ) if and only if

$$
\mu d>(1-\lambda) /\left.\left(1+3 \beta \tau^{2}\right)^{2}\right|_{\tau=\tau^{*}(\beta)} .
$$

(iii) For $\beta \rightarrow \infty$, the optimal tax vanishes, i.e., it is $\tau^{*}(\infty)=0$.

Part (i) implies that the optimal social welfare without innovation is

$$
\bar{W}_{0, \operatorname{Tax}}^{*}=-\frac{\mu d e_{0}^{2}}{1+\mu d}-\frac{d \sigma_{\varepsilon}^{2}}{2} .
$$




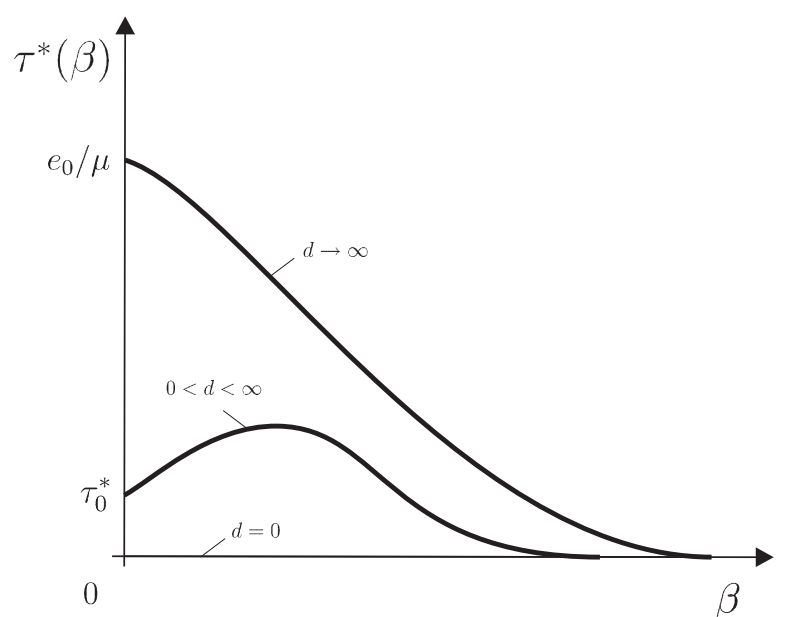

Fig. 1. Optimal carbon tax as a function of $\beta$ and $d$ (for $0 \leq \lambda<1$ ).

The maximum tax $\tau_{\max }^{*}=\max _{\beta \geq 0} \tau^{*}(\beta)$ follows directly from part (ii) when the inequality is either replaced by an equality or satisfied everywhere (in which case $\tau_{0}^{*}$ is maximal), so that

$$
\tau_{\max }^{*}= \begin{cases}\tau_{0}^{*} & \text { if } \mu d \geq 1-\lambda, \\ \sqrt{\frac{1}{3 \beta_{m}}\left[\sqrt{\frac{1-\lambda}{\mu d}}-1\right]_{+}} & \text {otherwise, }\end{cases}
$$

it is imposed where $\beta=\beta_{m} \equiv \inf \left\{\hat{\beta} \geq 0: \mu d \geq(1-\lambda) /\left.\left(1+3 \hat{\beta} \tau^{2}\right)^{2}\right|_{\tau=\tau^{*}(\hat{\beta})}\right\}$. The fact that the optimal carbon tax is (as long as $\lambda<1$ ) generally nonmonotonic in innovation effectiveness, as shown in Fig. 1, is noteworthy. It is obtained by providing a condition on the model parameters for which the objective function $\bar{W}$ exhibits decreasing differences in $(\tau, \beta){ }^{19}$

The constant $\lambda$ was introduced in Eq. (12) as a weight that describes the regulator's concern with the aggregate cost of innovation. For example, when $\lambda=1$ the regulator considers all of the cost to be societal, whereas when $\lambda=0$ the regulator thinks of innovation expenditures as fully offset by private benefits, ${ }^{20}$ so that they do not figure in social welfare. The value $1-\lambda$ is therefore the percentage of the aggregate innovation cost that society does not consider as lost because of the compensating benefits to social welfare. When the firms are fairly inefficient at the outset (so that $\mu<(1-\lambda) / d$ ), then the tax level is increasing in $\beta$ as long as the innovation effectiveness $\beta$ does not exceed $\beta_{m}$. Intuitively, increasing the tax level contributes to increasing abatement through innovation, $A_{I}=p^{2} \beta A_{0}$. When $\beta$ becomes large, i.e., $\beta>\beta_{m}$, the tax level $p$ decreases in innovation effectiveness, because $A_{I}=p^{2} \beta A_{0}=\mu p^{3} \beta$ remains finite, so that necessarily $p \rightarrow 0^{+}$as $\beta \rightarrow \infty$. If the regulator considers all of the innovation cost as social cost (for $\lambda=1$ ), the optimal tax is decreasing in the innovation effectiveness $\beta$.

Example 1. Consider an economy where the firms' marginal cost types are distributed such that $\mu=33 \times 10^{6}\left(\mathrm{tCO}_{2}\right)^{2} / \$^{2}$, $\sigma_{\theta}=3.3 \times 10^{6}\left(\mathrm{tCO}_{2}\right)^{2} / \$^{2}$, the innovation-cost coefficient is $c=\$ 100 \times 10^{9} /$ (unit of relative improvement), and the environmental damage function is characterized by $d=\$ 3.3 \times 10^{-9} /\left(\mathrm{tCO}_{2}\right)^{2}$. Then for an annual aggregate BAU emissions level of $e_{0}=13.5 \times 10^{9} \mathrm{tCO}_{2}$, corresponding to the combined OECD emissions [23], we obtain that $\tau_{0}^{*} \approx \$ 40.17 /\left(\mathrm{tCO}_{2}\right)$. Furthermore, with a resulting innovation effectiveness of $\beta \approx 0.167 \times 10^{-3}\left(\mathrm{tCO}_{2}\right)^{2} / \$^{2}$, the optimal carbon tax (determined numerically), $\tau^{*}(\beta) \approx \$ 45.61 /\left(\mathrm{tCO}_{2}\right)$, increases by about $13 \%$ over its level without innovation, for $\lambda=0$. If the regulator considers the innovation cost as social expenses, i.e., when $\lambda=1$, the optimal carbon tax drops to $\tau^{*}(\beta) \approx \$ 39.19 /\left(\mathrm{tCO}_{2}\right)$. The resulting expected aggregate emissions are $\bar{Q}_{0}^{*} \approx 12.17 \times 10^{9} \mathrm{tCO}_{2}$ without innovation, and $\bar{Q}^{*}(\beta) \approx 12.0 \times 10^{9} \mathrm{tCO}_{2}$ for $\lambda=0\left(\right.$ resp. $\bar{Q}^{*}(\beta) \approx 12.21 \times 10^{9} \mathrm{tCO}_{2}$ for $\left.\lambda=1\right)$ with innovation.

\subsection{Basic cap-and-trade (without price controls)}

We now consider the special case where the regulator chooses a 'basic' cap-and-trade scheme without binding price bounds, by setting $L=0$ and $U=\infty$. Then the market price for carbon depends only on the emissions cap $E$ and the realization of the macroeconomic uncertainty $\varepsilon$, i.e., $p=p(\varepsilon, E)=\eta p_{0}(\varepsilon, E)$. It is determined by the market-clearing condition (10), which

\footnotetext{
${ }^{19}$ For more intuition, see the discussion following Proposition 2 below.

${ }^{20}$ Such private benefits may accrue to an innovating firm through licensing [8].
} 
can be written in the form

$$
p_{0}(\varepsilon, E)-p(\varepsilon, E)-\beta p^{3}(\varepsilon, E)=0 .
$$

Proposition 2 (Optimal emissions cap). For any $\beta \geq 0$, let $E^{*}(\beta)$ be the optimal emissions cap in the absence of price controls.

(i) In the absence of innovation, i.e., when $\beta=0$, the optimal emissions cap is

$$
E^{*}(0)=\frac{e_{0}}{1+\mu d} \equiv E_{0}^{*}
$$

(ii) As the firms' innovation effectiveness $\beta$ increases, the optimal emissions cap $E^{*}(\beta)$ decreases.

(iii) For $\beta \rightarrow \infty$, the optimal emissions cap vanishes, i.e., $E^{*}(\infty)=0$.

In the absence of innovation, Eq. (15) and part (i) of Propositon 1 imply that the expected price is the same as the optimal tax without innovation computed in the previous section,

$$
\bar{p}_{0}^{*}=\mathbb{E}\left[p_{0}\left(\tilde{\varepsilon}, E_{0}^{*}\right) \mid E_{0}^{*}\right]=\left(e_{0}-E_{0}^{*}\right) / \mu=\tau_{0}^{*} .
$$

The corresponding optimal expected social welfare is

$$
\bar{W}_{0, \text { Basic C\&T }}^{*}=-\frac{\mu d e_{0}^{2}}{1+\mu d}-\frac{\sigma_{\varepsilon}^{2}}{2 \mu} \text {. }
$$

Part (ii) of Proposition 2 characterizes the behavior of the solution in $\beta$. Since this paper contains several such monotone comparative statics results, we provide the intuition underlying the proof. The proofs of other such results (cf. Propositions 1 (ii) and 4 (ii), (iii)) follow along similar lines. Via implicit differentiation of the market-clearing condition (23), we obtain that $p_{E}, p_{\beta}<0<p_{\beta E}$ (see Eqs. (26)-(28) in Appendix for the exact expressions), where subscripts denote partial derivatives. That is, when the carbon market clears, the market price $p$ decreases in the emissions cap $E$ and innovation effectiveness $\beta$, it also exhibits increasing differences in $(\beta, E)$, which means that the price decrease in $E$ (resp. $\beta$ ) is moderated when $\beta$ (resp. E) increases. Furthermore, since $p$ is nonnegative and decreasing in both $\beta$ and $E$, any (positive integer) power of $p$ also has increasing differences in $(\beta, E)$. Using the previous relations, expected abatement cost $\bar{C}$ can easily be shown to have increasing differences in $(\beta, E)$, while $\bar{D}$ does not depend on $\beta$ for a given emissions cap. Thus, the expected social welfare $\bar{W}$ has decreasing differences in $(\beta, E)$, so that the optimal $E$ is decreasing in $\beta$. In other words, as innovation becomes more effective ( $\beta$ increases), it is optimal to impose a more stringent emissions cap, i.e., $E^{*}(\beta)$ is decreasing in $\beta$ (cf. Fig. 2).

Example 2. Using the same values for $\mu, \sigma_{\theta}, c, d$, and $e_{0}$ as in Example 1, we obtain an optimal emissions cap of $E_{0}^{*} \approx 12.2 \times 10^{9} \mathrm{tCO}_{2}$. Because $\mu d \approx 0.11<1$, a carbon tax is superior to a pure emissions cap in terms of expected welfare. Furthermore, with an innovation effectiveness of $\beta \approx 0.167 \times 10^{-3}\left(\mathrm{tCO}_{2}\right)^{2} / \$^{2}$, and a uniform distribution of the macroeconomic uncertainty on $[-\delta, \delta]$ (where $\left.\delta=(10 \%) \cdot e_{0}\right)$, the optimal emissions cap $E^{*}(\beta) \approx 11.1 \times 10^{9}$ tCO for $\lambda=0$

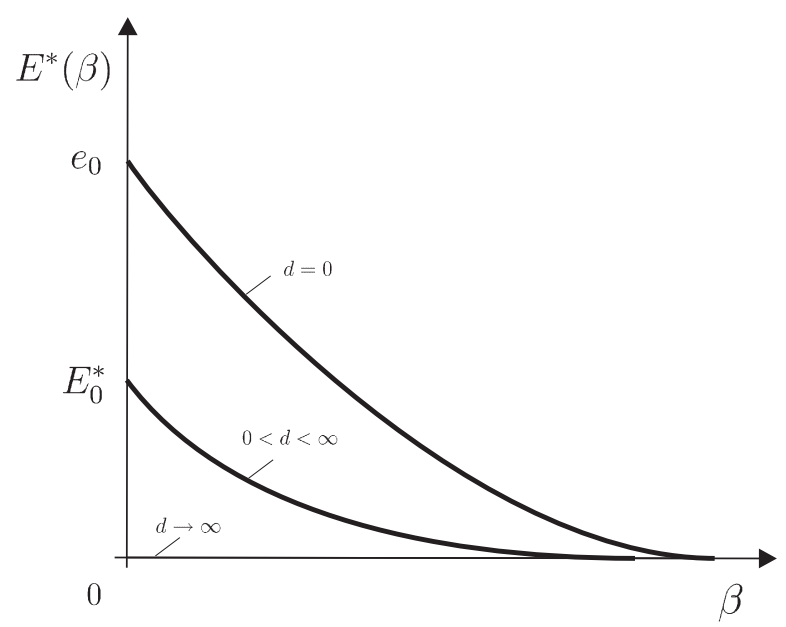

Fig. 2. Optimal emissions cap as a function of $\beta$ and $d$. 
(resp. $E^{*}(\beta) \approx 11.78 \times 10^{9} \mathrm{tCO}_{2}$ for $\lambda=1$ ) with innovation is more stringent than the optimal emissions cap $E_{0}^{*}$ without innovation.

\subsubsection{Comparison between pure taxation and basic cap-and-trade}

Price fluctuations have a detrimental impact on social welfare compared to pure taxation if environmental damages are small, i.e., when $\mu d<1$. Indeed, as shown by Weitzman [60], the difference in optimal expected welfare levels

$$
\bar{W}_{0, \mathrm{Tax}}^{*}-\bar{W}_{0, \mathrm{Basic} \mathrm{C} \& \mathrm{~T}}^{*}=(1-\mu d) \frac{\sigma_{\varepsilon}^{2}}{2 \mu},
$$

favors a carbon tax over the basic cap-and-trade scheme if and only if $\mu d<1$, i.e., if and only if the slope of marginal environmental damages is small compared to the (average) marginal abatement cost. $^{21}$ With the introduction of innovation, i.e., when $\beta>0$, the scales gradually tip towards quantity-based regulation, no matter how environmental

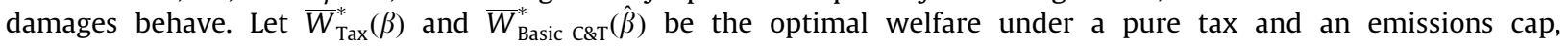
respectively.

Proposition 3 (Pure taxation vs. basic cap-and-trade).

(i) An increase in $\beta$ increases the relative attractiveness of quantity-based regulation over pure taxation, i.e., there exists a $\bar{\beta}>0$ such that

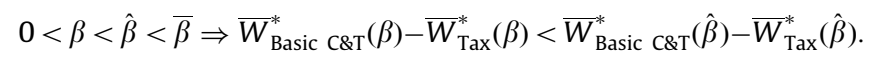

(ii) For large levels of innovation effectiveness, i.e., as $\beta \rightarrow \infty$, quantity-based regulation strictly dominates pure taxation, so that $0=\bar{W}_{\text {Basic } C \& \mathrm{~T}}^{*}(\infty)>\bar{W}_{\text {Tax }}^{*}(\infty)=-d \sigma_{\varepsilon}^{2} / 2$.

With increasing innovation effectiveness abatement goes up and aggregate emissions tend to zero under either of the two regulatory schemes. The intuition for part (i) of Proposition 3 is that while expected social welfare is increasing under both regulatory policies, the increase is slower under pure taxation. With innovation firms perceive price uncertainty as positive, because the upside to a higher price is a disproportionately larger benefit from abating carbon and thus a higher expected return on innovation (the technical reason being that firms' payoffs are convex in the market price, which implies a preference for increases in risk). In the extreme, a fixed carbon tax does not respond to the macroeconomic uncertainty, which leads to residual emissions (or overabatement) and therefore to positive environmental damages, whereas quantityregulation forces aggregate emissions to zero.

Remark 5. For any $\beta$, let $\bar{W}_{\text {Tax }}(E ; \beta)$ and $\bar{W}_{\text {Basic C\&T }}(\tau ; \beta)$ be the expected welfare under a pure tax and a basic cap-and-trade scheme, respectively. The market-clearing condition (23) then implies that

$$
\max _{E \geq 0} \bar{W}_{\text {Basic C\&T }}(E ; \beta)=\max _{\tau \geq 0} \mathbb{E}\left[\bar{W}_{\text {Basic C\&T }}\left(e_{0}+\tilde{\varepsilon}-\mu \tau\left(1+\beta \tau^{2}\right) ; \beta\right) \mid \tau\right] .
$$

Similarly, the relation between price and aggregate emissions in Eq. (6) yields that

$$
\max _{\tau \geq 0} \bar{W}_{\operatorname{Tax}}(\tau ; \beta)=\max _{E \geq 0} \mathbb{E}\left[\bar{W}_{\operatorname{Tax}}(p(\tilde{\varepsilon}, E) ; \beta) \mid E\right] .
$$

In other words, finding the optimal tax is equivalent to finding an emissions cap that maximizes the expected welfare subject to market clearing (23), and finding the optimal emissions cap is the same as optimizing the expected welfare subject to the output relation (6).

\subsection{Cap-and-trade (with price controls)}

Let us now consider the general case where the regulator can specify the cap-and-trade scheme $R=(E, L, U)$ with price controls. Clearly, this scheme cannot perform worse than any of the two regulatory policies considered above. The extant theoretical literature has focussed on the effect of a price ceiling [30,48], which by Eqs. (20) and (21) reduces expected aggregate costs, but at the same time tends to increase expected aggregate damages. The introduction of price ceilings therefore tends to convert abatement-cost uncertainty into environmental-damage uncertainty. As a result it may be optimal to increase or decrease the emissions cap, depending on how fast marginal environmental damages increase. A price floor, on the other hand, tends to increase expected aggregate abatement costs and decrease expected aggregate damages, and therefore produces a countervailing effect on the optimal emissions cap.

\footnotetext{
${ }^{21}$ Strictly speaking, the expected marginal cost $\int_{\Theta}(1 / \theta) d F(\theta)$, which may vary somewhat from $1 / \mu$, is relevant to the comparison with the slope of marginal environmental damages $d$.
} 


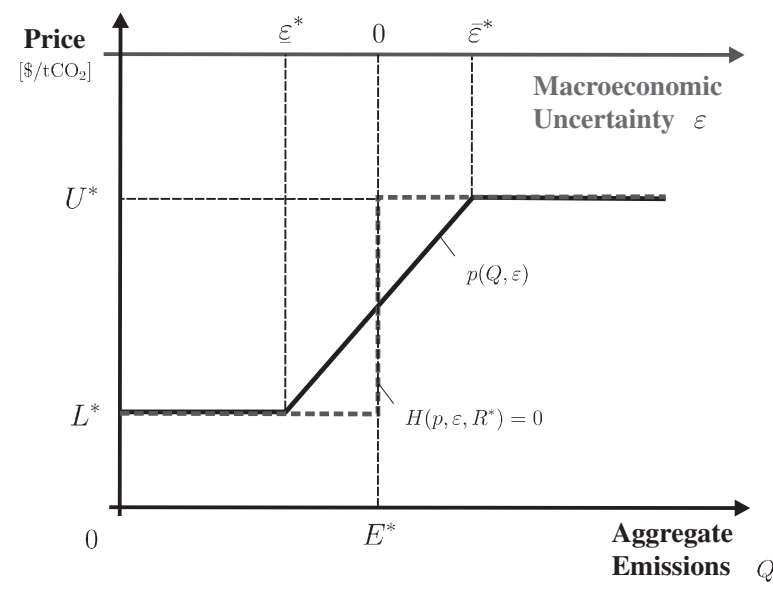

Fig. 3. Cap-and-trade with price controls.

Proposition 4 (Optimal cap-and-trade with price controls).

(i) In the absence of innovation, i.e., when $\beta=0$, the optimal regulatory policy is

$$
R^{*}=\left(E_{0}^{*}, L_{0}^{*}, U_{0}^{*}\right)=\left(\frac{e_{0}}{1+\mu d}, d \cdot e_{0}+\mathbb{E}\left[\tilde{\varepsilon} \mid \tilde{\varepsilon} \leq \frac{\left.\underline{\varepsilon}^{*}\right]}{1+\mu d}, d \cdot \frac{e_{0}+\mathbb{E}\left[\tilde{\varepsilon} \mid \tilde{\varepsilon} \geq \bar{\varepsilon}^{*}\right]}{1+\mu d}\right),\right.
$$

where the optimal uncertainty thresholds $\bar{\varepsilon}^{*}=\bar{\varepsilon}\left(E_{0}^{*}, U_{0}^{*}\right)$ and $\underline{\varepsilon}^{*}=\underline{\varepsilon}\left(E_{0}^{*}, L_{0}^{*}\right)$ are given by Eqs. (16) and (17), respectively. For parts (ii) and (iii), assume that the density of the macroeconomic uncertainty $\tilde{\varepsilon}$ is nondecreasing on its support. ${ }^{22}$

(ii) With increasing innovation effectiveness $\beta$, the optimal emissions cap $E^{*}(\beta)$ decreases.

(iii) With increasing innovation effectiveness $\beta$, the optimal price controls $L^{*}(\beta)$ and $U^{*}(\beta)$ tighten for small $d$ and loosen for large $d$.

The workings of an optimal cap-and-trade market design with price controls as a function of the macroeconomic uncertainty $\varepsilon$ and aggregate emissions $Q$ are illustrated in Fig. 3. For $\beta=0$ (i.e., without innovation), the optimal emissions cap $E_{0}^{*}$ is unaffected by the optimal price controls and identical to the one determined earlier, in Section 3.2. The price controls are symmetric to the marginal environmental damages $d E_{0}^{*}$ if the distribution of macroeconomic uncertainty is symmetrical. The width of the interval depends on the thickness of the tails of that distribution and on the magnitude of the product $\mu \mathrm{d}$. The latter is also decisive in determining the tradeoff between pure taxation $(\mu d<1)$ and quantity-based regulation $(\mu d>1)$, as analyzed before. With increases in $\mu d$, not only does the regulator set a lower emissions cap, but also price controls are loosened around $d E_{0}^{*}$. Part (ii) of the last result states that, all else being equal, innovation always leads to a more stringent emissions target. In part (iii) of Proposition 4, it becomes evident that the evolution of the price controls as a function of innovation effectiveness is somewhat more complicated. First, the price cap and price adjust to changes of $\beta$ in opposite directions, either tightening or widening the interval of admissible prices in the market for carbon permits. Second, for small $d$ price controls tighten with increasing $\beta$, i.e., $L^{*}(\beta)$ increases and $U^{*}(\beta)$ decreases. Third, for large $d$, it is best for the regulator to respond to an increase in $\beta$ by relaxing price controls, so that $L^{*}(\beta)$ decreases and $U^{*}(\beta)$ increases. Combining the last two points, we see that the sensitivity of the optimal regulatory scheme to the magnitude of the slope of marginal environmental damages $d$ increases with increasing $\beta$ (cf. Fig. 4). This makes sense and directly corresponds to the classical tradeoff by Weitzman. But this time it is related to the regulatory response to innovation. Depending on the magnitude of the environmental damages, an increase of innovation effectiveness may prompt a regulator to impose more or less price control, a decision which becomes more sensitive to the magnitude of marginal environmental damages.

Remark 6. Even for extremely large damage cost, the corresponding limits for the price bounds are well-defined, as $\lim _{d \rightarrow \infty} U_{0}^{*}=\left(e_{0}+\mathbb{E}[\tilde{\varepsilon} \mid \tilde{\varepsilon} \geq \bar{\varepsilon}]\right) / \mu$ and $\lim _{d \rightarrow \infty} L_{0}^{*}=\left(e_{0}+\mathbb{E}[\tilde{\varepsilon} \mid \tilde{\varepsilon} \leq \bar{\varepsilon}]\right) / \mu$.

Example 3. If the macroeconomic random shock $\tilde{\varepsilon}$ is uniformly distributed on $[-\delta, \delta]$ for some $\delta>0$, then in the absence of innovation the optimal carbon emissions cap is $E_{0}^{*}=e_{0} /(1+\mu d)$, while the optimal price controls are $U_{0}^{*}=d\left(e_{0} /(1+\mu d)+\delta /(2+\mu d)\right)$ and $L_{0}^{*}=d\left(e_{0} /(1+\mu d)-\delta /(2+\mu d)\right)$. Using the same values for $\mu, \sigma_{\theta}, c, d$, $e_{0}$, and $\lambda$ as in Example 1 and 2 , in the absence of innovation we obtain an optimal emissions cap $E_{0}^{*} \approx 12.2 \times 10^{9} \mathrm{tCO}_{2}\left(\right.$ as in $\mathrm{Example}_{2}$ )

\footnotetext{
${ }^{22}$ This condition is simple and sufficient; it is satisfied, e.g., for a uniform distribution of the macroeconomic uncertainty on a compact support. Much less is required, as can be seen by inspecting the proof of Proposition 4.
} 


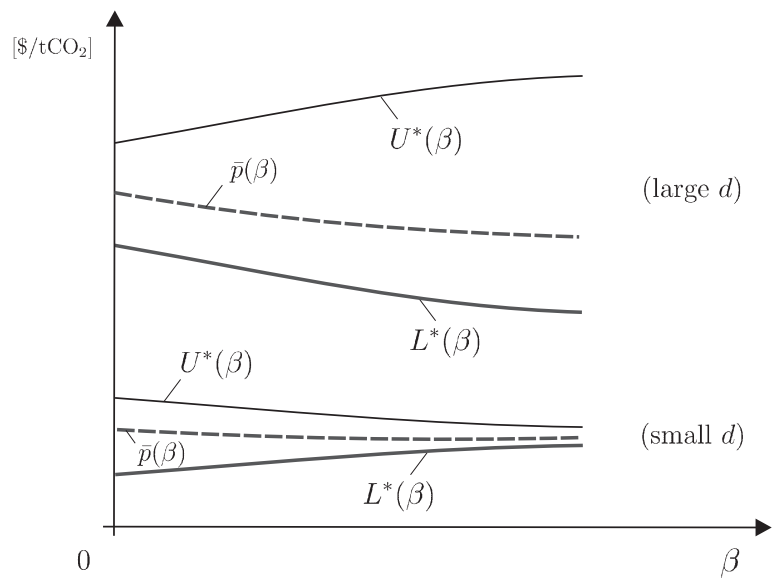

Fig. 4. Price controls as a function of innovation effectiveness $\beta$ (for $d$ small/large).

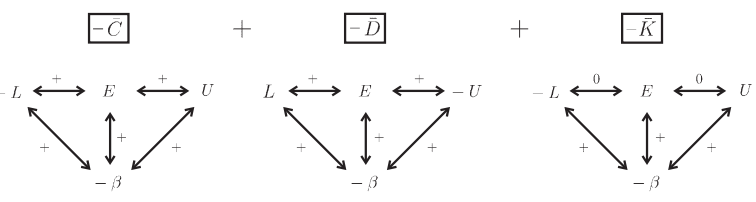

Fig. 5. Complementarity relationships in social welfare, $\bar{W}=-\bar{C}-\bar{D}-\bar{K}$.

with an optimal price control $\left(L_{0}^{*}, U_{0}^{*}\right) \approx(38,42) \$ / \mathrm{tCO}_{2}$. At an innovation effectiveness of $\beta \approx 0.167 \times 10^{-3}\left(\mathrm{tCO}_{2}\right)^{2} / \$^{2}$, and with $\delta=(10 \%) \times e_{0}$ as in Example 2, the optimal emissions cap becomes $E^{*}(\beta) \approx 11.5 \times 10^{9} \mathrm{tCO}_{2}$ with the loosened price control $\left(L^{*}(\beta), U^{*}(\beta)\right) \approx(42.8,48.6) \$ / \mathrm{tCO}_{2}$, for $\lambda=0$ (resp. $E^{*}(\beta) \approx 11.9 \times 10^{9} \mathrm{tCO}_{2}$ and $\left(L^{*}(\beta), U^{*}(\beta)\right) \approx(37.2,41.3) \$ / \mathrm{tCO}_{2}$ for $\lambda=1)$.

\subsubsection{Comparative statics for policy adjustments}

It is perhaps unrealistic to expect that a political process can produce optimal values for all components of a regulatory policy, so that $R^{*}=\left(E^{*}, L^{*}, U^{*}\right)$ is actually implemented. More likely is a scenario under which a political debate is informed by the model solution but one or more elements of the resulting compromise are moved away from the model-predicted normative outcome, e.g., because they satisfy the special interests of certain stakeholders. This implies the natural question of how the remaining components should be adjusted so as to achieve the 'constrained optimality' of the free elements. The proof of the last parts of Proposition 4 helps answer questions of the sort, "what happens to the optimal price floor and the optimal emissions cap when the price ceiling is changed?' The latter adjustment may be needed for political reasons or for achieving harmonization between different cap-and-trade schemes in neighboring countries, despite the prima facie welfare losses in a single country.

As pointed out by Milgrom and Roberts [31], based on earlier findings by Topkis [58], among others, the monotonicity of optimal decisions (on lattices) critically depends on the supermodularity properties of the objective function in the decision variables and parameters. ${ }^{23}$ In case supermodularity does not obtain under the initial problem parametrization, one may use an appropriate parameter (or variable) transformation [56]. Such a transformation turns out to be very simple, as several sign reversals are enough to establish supermodularity of each of the components $(-\bar{C},-\bar{D}$, and $-\bar{K})$ of the expected social welfare $\bar{W}$.

The complementarity relationships between the decision variables and innovation effectiveness as well as marginal environmental damage, as determined by the sign of the cross-partial derivatives, are summarized by the diagrams in Fig. 5. We see that both $-\bar{C}$ and $-\bar{K}$ are supermodular (have positive cross-partial derivatives) in $(E,-L, U,-\beta$ ), whereas $-\bar{D}$ is supermodular in $(E, L,-U, D)$. Thus, when expected damages dominate in the social welfare, i.e., when $d$ is large, then monotone comparative statics obtain according to the complementarity properties of $\bar{D}$. When $d$ is small, then the complementarity properties of $\bar{C}$ determine the comparative statics. Fig. 5 is also useful for determining the direction of adjustments to the remaining policy instruments when one of them is changed exogenously. For example, when the price ceiling $U$ is increased and the slope of marginal environmental damage cost $d$ is fairly large, then the optimal emissions cap decreases (opposite direction as change in price cap, for the relation between $E$ and $-U$ in $-\bar{D}$ has a positive sign, as

\footnotetext{
${ }^{23}$ Milgrom and Shannon [32] show that quasi-supermodularity of the objective function is a sufficient (and in some sense necessary) condition for the monotonicity of solutions in parameters.
} 


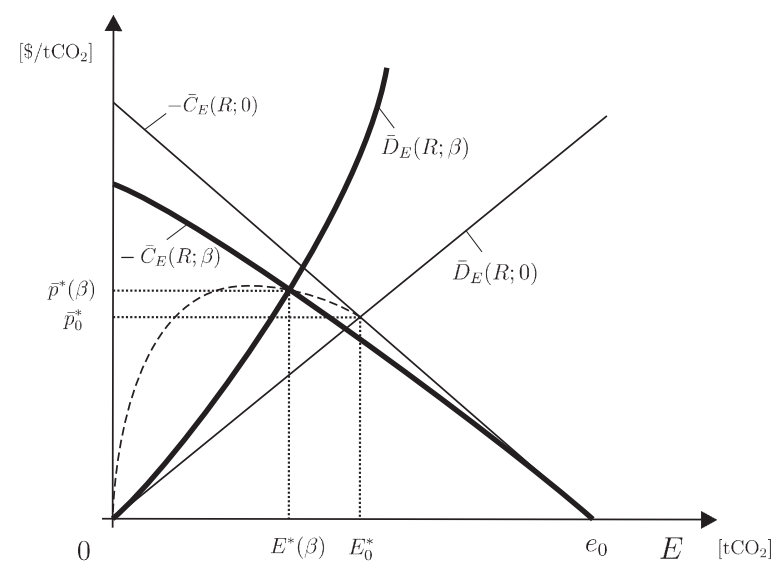

Fig. 6. Expected market price $\bar{p}^{*}(\beta)$ as a function of innovation effectiveness $\beta$.

indicated by the '+' at the corresponding double-arrow), so that the relation between $E$ and $U$ is negative. Furthermore, the optimal price floor increases (opposite direction compared to change in price cap, as the relation between $E$ and $L$ in $-\bar{D}$ has a positive sign).

\section{Policy implications}

A substantial private investment is needed to significantly reduce carbon emissions into the atmosphere. Effective regulatory schemes therefore need to take into account not only the firms' emissions decisions, but also the return on their R\&D investments. A price floor guarantees a minimum return on innovation, whereas a price cap reduces the volatility in aggregate abatement costs. The last section has shown that changes in the firms' propensity to innovate are likely to have a profound impact on the optimal design of carbon taxes as well as on cap-and-trade markets, with or without price controls. It has also made clear that a higher innovation effectiveness tends to increase the attractiveness of cap-and-trade schemes vs. carbon taxes. This is due to the fact that when prices increase (cf. Fig. 6), the substitution of emissions uncertainty for price uncertainty by imposing a tighter quantity control serves as an additional innovation incentive, while when prices decrease, the savings in abatement cost become so large that the regulator's only worry is the uncertainty in environmental damages, thus calling for a quantity control.

The introduction of price controls in cap-and-trade markets, while superior to basic cap-and-trade in a simplified modelling framework, is subject to a number of political considerations. First, the determination of a price cap in a political process is likely to lead to substantial influence activities by affected parties during the course of the legislative process, which may therefore produce price caps that are too low or price floors that are too high as a result of "political compromises.' Second, environmental damages depend on aggregate carbon and other greenhouse gas emissions irrespective of their origin. This implies the need for a coordinated response and therefore government intervention, and international cooperation. If emissions targets are coordination devices for international cooperation, then policy mechanisms (e.g., cap-and-trade schemes without price ceilings) can enhance the ability of governments to comply with commitments to future generations and investors in low-carbon alternatives. A negative side-effect of price controls may be that they create challenges for the harmonization of cap-and-trade schemes with different price controls, and may even lead to arbitrage opportunities in cross-border trade of emissions permits.

Given the above caveats, what are the potential benefits of additional price controls? ${ }^{24}$ Price caps reduce expected aggregate costs as well as the social cost of innovation, as can be seen directly from Eqs. (20) and (22). At the same time they tend to increase expected environmental damages. Decreasing an existing price cap decreases the optimal emissions cap, as long as $d$ is small. For large $d$, the opposite holds true. Thus, the degree to which a more stringent policy can be pursued by introducing a price cap depends on the relative magnitude of the slope of environmental damage cost. Price floors, on the other hand, offer a government-backed minimum value for emissions permits. This encourages innovation. Price floors reduce the downside risk from low carbon prices for investors in new abatement technologies. As investors tend to be risk-averse and concerned particularly with such downside risks, price floors can help justify the pursuit of 'low-carbon projects.'

\footnotetext{
${ }^{24}$ Indirect methods of 'price stabilization,' for example through the use of buffer stocks, were suggested in great detail by Newbery and Stiglitz [37]. In this spirit, it may be possible to relax direct price controls if one allows for emissions banking to create buffers moderating price fluctuations that would otherwise result from the shocks in BAU emissions levels driven by macroeconomic uncertainty. A multi-period emissions-trading framework is needed to address this question.
} 


\section{Conclusion}

In the absence of innovation, the classical Weitzman [60] result states that under uncertainty the relative magnitude of the slopes of marginal abatement costs and marginal environmental damage costs is crucial for deciding between tax-based or quantity-based policy instruments. When the slope of marginal environmental damage cost $d$ is larger than the slope of (expected) marginal abatement costs $1 / \mu$, quantity-based regulation is preferable. The best instrument attempts to parallel marginal welfare as a function of the uncertainty. Weitzman's classical framework allows only for one degree of freedom, either the choice of the emissions cap or the choice of the carbon price. Introducing additional degrees of freedom through price controls in a cap-and-trade market allows one first to replicate each of the two simple schemes and then to improve welfare over both schemes.

We assume that firms can invest in innovation and thus reduce the cost of mitigation efforts. This enables them to mitigate more carbon at the same price of carbon. With additional mitigation opportunities the marginal abatement cost is reduced. This shifts the tradeoff between marginal abatement cost and marginal environmental damage cost. The optimal emissions cap decreases in innovation effectiveness. In the presence of innovation we observe two additional results. First, carbon prices create incentives for innovation in mitigation technologies. A welfare-optimal carbon policy targets an emissions level at which the innovation-enhanced marginal mitigation cost curve (considering expected innovation) intersects the damage curve that includes the additional benefits from incentives for innovation. As a result, the optimal carbon price in the world with innovation can be higher than in the world without innovation. Second, the model shows that with increasing innovation, price controls are tightened when marginal environmental damage costs are low, and relaxed when these costs are large. Innovation creates mitigation opportunities that reduce the slope of the mitigation cost curve and therefore make the optimal instrument look more like a cap (e.g., wider spreads).

In the current discussion on price caps and floors, the analysis often focuses on static models. Including additional dimensions can materially alter the results. For example, the potential for innovation can increase the level at which caps and floors are set. We note that the analysis in this paper neglected several global effects of price caps, such as the question of what happens when they are set in a world of uncertain fuel and technology prices. The political debate surrounding price controls as additional policy instruments is complex. For example, Pizer [48], among others, pointed out that price caps can increase the likelihood of governments accepting more stringent targets. On the other hand, price caps, through implicit borrowing from future periods, may reduce the incentive for governments or private companies to comply with emissions targets and can subsequently create incentives to default on long-term emissions targets that would require repayment of carbon debt. More elaborate models are required to examine such effects in greater detail.

\section{Acknowledgments}

The authors would like to thank Michael Grubb, Arun Malik, David Newbery, Nicholas Stern, two anonymous reviewers, as well as participants of the 24th Annual Congress of the European Economic Association, and the Energy and Environment Seminar at the University of Cambridge for helpful comments and discussion. Support by the British Academy, the Precourt Energy Efficiency Center at Stanford University, and the UK Research Councils is gratefully acknowledged. A major portion of this research was conducted while the first author was an official visitor at the Department of Economics, University of Cambridge.

\section{Appendix A. Proofs}

Proof of Proposition 1. (i) Let $R=\left(e_{0}, \tau, \tau\right)$. The corresponding expected social welfare,

$$
\bar{W}(\tau ; \beta)=-\frac{\mu}{2}\left(1+\beta \tau^{2}\right) \tau^{2}-\frac{d}{2}\left[\sigma_{\varepsilon}^{2}+\left(e_{0}-\mu \tau\left(1+\beta \tau^{2}\right)\right)^{2}\right]-\lambda \frac{\mu \beta \tau^{4}}{4},
$$

is strictly concave in the tax level $\tau$. In the absence of innovation it is $\beta=0$, so that

$$
\bar{W}(\tau ; 0)=-\frac{\mu \tau^{2}}{2}-\frac{d}{2}\left[\sigma_{\varepsilon}^{2}+\left(e_{0}-\mu \tau\right)^{2}\right],
$$

and the unique optimal tax becomes $\tau_{0}^{*}=d e_{0} /\left(1+\mu d\right.$ ). (ii) For $\beta>0$, the optimal tax $\tau^{*}(\beta)$ is determined by the first-order necessary optimality condition $\bar{W}_{\tau}\left(\tau^{*}(\beta) ; \beta\right)=0{ }^{25}$ Differentiating this condition implicitly with respect to $\beta$ yields $d \tau^{*}(\beta) / d \beta=-\bar{W}_{\tau \beta}\left(\tau^{*}(\beta) ; \beta\right) / \bar{W}_{\tau \tau}\left(\tau^{*}(\beta) ; \beta\right)$. Since $\bar{W}_{\tau \tau}\left(\tau^{*}(\beta) ; \beta\right)<0$ at the welfare-maximizing tax level, the optimal tax $\tau^{*}(\beta)$ is decreasing if and only if $\bar{W}_{\tau \beta}\left(\tau^{*}(\beta) ; \beta\right)<0$. Combining $\bar{W}_{\tau \beta}(\tau ; \beta)=\mu \tau^{3}\left[\left(3 d e_{0} / \tau\right)-2\left(1+\mu d\left(2+3 \beta \tau^{2}\right)\right)+\lambda\right]$ with the fact that

\footnotetext{
${ }^{25}$ By Abel's impossibility theorem (see, e.g., [22], p. 308) a closed-form solution for $\tau^{*}(\beta)$ cannot be expected.
} 
by the first-order condition

$$
\frac{d e_{0}}{\tau}=\frac{1+(2+\lambda) \beta \tau^{2}+\mu d\left(1+\beta \tau^{2}\right)\left(1+3 \beta \tau^{2}\right)}{1+3 \beta \tau^{2}},
$$

we obtain that $\bar{W}_{\tau \beta}<0$ if and only if $\mu d>(1-\lambda) /\left(1+3 \beta \tau^{2}\right)^{2}$. (iii) Since $\lim _{\beta \rightarrow \infty} \bar{W}_{\tau}(\tau ; \beta) / \beta^{2}=-3 \mu^{2} d \tau^{5}=0$ at the optimal tax $\tau=\tau^{*}(\infty)$, we must have that $\tau^{*}(\infty)=0$, i.e., the optimal tax converges to zero as perfect abatement becomes free.

Proof of Proposition 2. (i) Let $R=(E, 0, \infty)$. The expected social welfare in this case is

$$
\bar{W}(E ; \beta)=-\mathbb{E}\left[\frac{\mu}{2}\left(1+\beta p^{2}(\tilde{\varepsilon}, E)\right) p^{2}(\tilde{\varepsilon}, E)+\frac{d E^{2}}{2}+\frac{\lambda \mu \beta p^{4}(\tilde{\varepsilon}, E)}{4}\right],
$$

where $p(\varepsilon, E)=\eta p_{0}(\varepsilon, E)$ as in Eq. (14). In the absence of innovation, i.e., for $\beta=0$, it is

$$
\bar{W}(E ; 0)=-\frac{\left(e_{0}-E\right)^{2}}{2 \mu}-\frac{d E^{2}}{2}-\frac{\sigma_{\varepsilon}^{2}}{2 \mu},
$$

strictly concave in $E$, leading to a unique optimal emissions cap of $E_{0}^{*}=e_{0} /(1+\mu d)$. (ii) For $\beta>0$, the optimal emissions cap $E^{*}(\beta)$ is implicitly determined by the first-order necessary optimality condition

$$
\bar{W}_{E}\left(E^{*}(\beta), \beta\right)=0 .
$$

Differentiating Eq. (25) on both sides with respect to $\beta$, we obtain that

$$
\frac{d E^{*}(\beta)}{d \beta}=-\frac{\bar{W}_{E \beta}\left(E^{*}(\beta) ; \beta\right)}{\bar{W}_{E E}\left(E^{*}(\beta) ; \beta\right)} .
$$

By differentiating the market-clearing condition (23) it is

$$
\begin{aligned}
& p_{E}=-\frac{1}{\mu} \frac{1}{1+3 \beta p^{2}}, \\
& p_{\beta}=-\frac{p^{3}}{1+3 \beta p^{2}}, \\
& p_{E \beta}=\frac{3 p^{2}}{\mu} \frac{1+\beta p^{2}}{\left(1+3 \beta p^{2}\right)^{3}},
\end{aligned}
$$

so that

$$
\bar{W}_{E \beta}\left(E^{*}(\beta) ; \beta\right)=\mu \mathbb{E}\left[-(\lambda+2 \mu)\left(p^{3}+3 \beta p^{2} p_{\beta}\right) p_{E}-(\lambda+2 \mu) \beta p^{3} p_{E \beta}-p_{\beta} p_{E}-p p_{E \beta}\right]=\mathbb{E}\left[\frac{\left(-4-3 \beta p^{2}+(2 \mu+\lambda)\left(1-\beta^{2} p^{4}\right)\right) p^{3}}{\mu\left(1+3 \beta p^{2}\right)^{3}}\right]<0,
$$

for all $\lambda \in[0,1]$ and all $\mu>0$ (with $p=p\left(\tilde{\varepsilon}, E^{*}(\beta)\right)$ ). Since $\bar{W}_{E E}\left(E^{*}(\beta) ; \beta\right)<0$ at the welfare-maximizing emissions cap, the fact that $\bar{W}_{E \beta}<0$ implies that the optimal emissions cap $E^{*}(\beta)$ is decreasing. (iii) Note first that $p(\infty)=0$, i.e., the market price for carbon vanishes for $\beta \rightarrow \infty$, which is obtained by taking the corresponding limit in the market-clearing condition (23). Thus, taking the limit in the first-order condition (25) implies that $E^{*}(\infty)=0$.

Proof of Proposition 3. (i) Given any $\beta>0$, let $\bar{W}_{\text {Tax }}(\tau ; \beta)$ and $\bar{W}_{\text {Basic C\&T }}(E ; \beta)$ be the expected welfare for a pure tax of $\tau$ and an emissions cap of $E$, respectively. At the optimal levels $\tau^{*}(\beta)$ and $E^{*}(\beta)$, an application of the envelope theorem yields that

$$
\frac{d}{d \beta}\left(\bar{W}_{\text {Tax }}^{*}(\beta)-\bar{W}_{\text {Basic C\&T }}^{*}(\beta)\right)=\frac{\mu}{2}\left(1-\frac{\lambda}{2}\right)\left(\left.\frac{\left(1+\left(\frac{2+\lambda}{2-\lambda}\right) \beta \tau^{2}\right) \tau^{4}}{1+3 \beta \tau^{2}}\right|_{\tau=\tau^{*}(\beta)}-\mathbb{E}\left[\frac{\left(1+\left(\frac{2+\lambda}{2-\lambda}\right) \beta \tilde{p}^{2}\right) \tilde{p}^{4}}{1+3 \beta \tilde{p}^{2}} \tilde{p}=p\left(\tilde{\varepsilon}, E^{*}(\beta)\right)\right]\right),
$$

where $\bar{W}_{\text {Tax }}^{*}(\beta)=\bar{W}_{\text {Tax }}\left(\tau^{*}(\beta) ; \beta\right), \bar{W}_{\text {Basic C\&T }}^{*}(\beta)=\bar{W}_{\text {Basic C\&T }}\left(E^{*}(\beta) ; \beta\right)$, and $p\left(\tilde{\varepsilon}, E^{*}(\beta)\right)=\eta p_{0}\left(\tilde{\varepsilon}, E^{*}(\beta)\right)$ as in Eq. (14). Taking the limit for $\beta \rightarrow 0+$ on both sides of the last equation, we obtain

$$
\left.\frac{d}{d \beta}\right|_{\beta=0}\left(\bar{W}_{\text {Tax }}^{*}(\beta)-\bar{W}_{\text {Basic C\&T }}^{*}(\beta)\right)=\frac{\mu}{2}\left(1-\frac{\lambda}{2}\right)\left(\left(\tau_{0}^{*}\right)^{4}-\mathbb{E}\left[\left(p_{0}\left(\widetilde{\varepsilon}, E_{0}^{*}\right)\right)^{4}\right]\right)<0,
$$

since $\tau_{0}^{*}=\mathbb{E}\left[p_{0}\left(\tilde{\varepsilon}, E_{0}^{*}\right)\right]$ by Eq. (24), and $\mathbb{E}\left[p_{0}\left(\tilde{\varepsilon}, E_{0}^{*}\right)\right]<\mathbb{E}\left[\left(p_{0}\left(\tilde{\varepsilon}, E_{0}^{*}\right)\right)^{4}\right]$ by Jensen's inequality (as long as there exists nontrivial macroeconomic uncertainty $\tilde{\varepsilon}$, so that $\left.\sigma_{\varepsilon}>0\right)$. From the continuity of the derivative of $\bar{W}_{\text {Tax }}^{*}(\beta)-\bar{W}_{\text {Basic C\&T }}^{*}(\beta)$ we can therefore conclude that there exists a $\beta_{0}>0$, such that $d / d \beta\left(\bar{W}_{\text {Tax }}^{*}(\beta)-\bar{W}_{\text {Basic C\&T }}^{*}(\beta)\right)<0$ for all $\beta \in\left(0, \beta_{0}\right)$. (ii) By taking the limit for $\beta \rightarrow \infty$ in Eq. (18) we obtain that $\lim _{\beta \rightarrow \infty} \eta=0$ for any positive $p_{0}$. Hence, Eq. (14) implies that $\lim _{\beta \rightarrow \infty} p\left(\varepsilon, E^{*}(\beta)\right)=\lim _{\beta \rightarrow \infty} \eta p_{0}\left(\varepsilon, E^{*}(\beta)\right)=0$ for all $\varepsilon$. Thus, using part (iii) of Proposition 2 together with Eq. (15) and the 
market-clearing condition (23), it is $\lim _{\beta \rightarrow \infty} p_{0}\left(\varepsilon, E^{*}(\beta)\right)=\mu \lim _{\beta \rightarrow \infty} \beta\left(p\left(\varepsilon, E^{*}(\beta)\right)\right)^{3}=e_{0}+\varepsilon$ for all $\varepsilon$. Therefore,

$$
\lim _{\beta \rightarrow \infty} \beta\left(p\left(\varepsilon, E^{*}(\beta)\right)\right)^{4}=\left(\lim _{\beta \rightarrow \infty} \beta\left(p\left(\varepsilon, E^{*}(\beta)\right)\right)^{3}\right)\left(\lim _{\beta \rightarrow \infty} p\left(\varepsilon, E^{*}(\beta)\right)\right)=0,
$$

which implies (after a legitimate switch of limit and integration) in Eqs. (20)-(22) $\left(\right.$ for $R=\left(E^{*}(\beta), 0, \infty\right)$ ) that $\lim _{\beta \rightarrow \infty} \bar{W}_{\text {Basic C\&T }}^{*}(\beta)=0$. On the other hand, by part (iii) of Proposition 1 it is $\tau^{*}(\infty)=0$, so that, using Eqs. (20) and (22), the social costs of innovation and aggregate abatement costs are zero. The key difference of pure taxation is that as innovation effectiveness goes to infinity, the (deterministic!) optimal tax level approaches zero, and at the same time the aggregate abatement approaches $e_{0}$, so that, using Eqs. (6) and (8), the aggregate emissions become

$$
\lim _{\beta \rightarrow \infty} Q\left(\tau^{*}(\beta), \varepsilon\right)=\lim _{\beta \rightarrow \infty}\left(e_{0}+\varepsilon-\mu \tau^{*}(\beta)\left(1+\beta\left(\tau^{*}(\beta)\right)^{2}\right)\right)=\varepsilon
$$

for all $\varepsilon$. Expected aggregate environmental damages are therefore equal to $-d \sigma_{\varepsilon}^{2} / 2$, so that

$$
\lim _{\beta \rightarrow \infty} \bar{W}_{\mathrm{Tax}}^{*}(\beta)=-\frac{d \sigma_{\varepsilon}^{2}}{2}<0=\lim _{\beta \rightarrow \infty} \bar{W}_{\text {Basic } \mathrm{C} \& \mathrm{~T}}^{*}(\beta),
$$

which concludes our proof.

Proof of Proposition 4. (i) We first consider the situation without innovation, where $\beta=0$ and where $\bar{W}(R ; 0)$ is the expected social welfare without innovation. Using the Leibniz rule, we obtain the first-order necessary optimality condition

$$
\frac{\partial \bar{W}(R ; 0)}{\partial E}=\int_{\underline{\varepsilon}}^{\bar{\varepsilon}}\left(\frac{1}{\mu}\left(e_{0}+\varepsilon-E\right)-d E\right) d G(\varepsilon)=0
$$

which is equivalent to $E_{0}^{*}=\left(e_{0}+\mathbb{E}[\tilde{\varepsilon} \mid \underline{\varepsilon} \leq \tilde{\varepsilon} \leq \bar{\varepsilon}]\right) /(1+\mu d)$. Similarly, we obtain

$$
\frac{\partial \bar{W}(R ; 0)}{\partial U}=\int_{\bar{\varepsilon}}^{\infty}\left(-\mu U+\mu d\left(e_{0}+\varepsilon-\mu U\right)\right) d G(\varepsilon)=0
$$

which is equivalent to $U_{0}^{*}=d \cdot\left(e_{0}+\mathbb{E}[\tilde{\varepsilon} \mid \tilde{\varepsilon} \geq \bar{\varepsilon}]\right) /(1+\mu d)$, and, analogously, $L_{0}^{*}=d \cdot\left(e_{0}+\mathbb{E}[\tilde{\varepsilon} \mid \tilde{\varepsilon} \leq \underline{\varepsilon}]\right) /(1+\mu d)$. (ii), (iii) We examine the supermodularity properties of the expected welfare $\bar{W}=-\bar{C}-\bar{D}-\bar{K}$ for each of its components. Consider first

$$
\bar{C}(R ; \beta)=\frac{\mu}{2} \int_{-\infty}^{\infty}\left(1+\beta p^{2}(\varepsilon, R)\right) p^{2}(\varepsilon, R) d G(\varepsilon)
$$

with

$$
\bar{C}_{\beta}(R ; \beta)=\frac{\mu}{2} \int_{\underline{\varepsilon}}^{\bar{\varepsilon}}\left(2\left(1+2 \beta p^{2}\right) p p_{\beta}+p^{4}\right) d G(\varepsilon)
$$

where $p_{\beta}$ is given in Eq. (27). Using Eqs. (26)-(28), we therefore find that

$$
\bar{C}_{\beta L}=-\frac{\mu^{2}}{2}\left(1+\beta L^{2}\right) L^{4} G^{\prime}(\underline{\varepsilon}) \leq 0 \leq \frac{\mu^{2}}{2}\left(1+\beta U^{2}\right) U^{4} G^{\prime}(\bar{\varepsilon})=\bar{C}_{\beta U},
$$

and

$$
\bar{C}_{\beta E}=2 \int_{\underline{\varepsilon}}^{\bar{\varepsilon}} \frac{\left(1+3 \beta p^{2}+3 \beta^{2} p^{4}\right) p^{3}}{\left(1+3 \beta p^{2}\right)^{3}} d G(\varepsilon)+\frac{\mu}{2}\left(\frac{\left(1+\beta U^{2}\right) U^{4} G^{\prime}(\bar{\varepsilon})}{1+3 \beta U^{2}}-\left(1+\beta L^{2}\right) L^{4} G^{\prime}\left(\frac{\underline{\varepsilon})}{1+3 \beta L^{2}}\right) .\right.
$$

Since, by hypothesis, the density $G^{\prime}(\varepsilon)$ is nondecreasing on its support, it is $G^{\prime}(\underline{\varepsilon}) \leq G^{\prime}(\bar{\varepsilon})$. Furthermore, it is easy to show that the function $x^{4}\left(1+\beta x^{2}\right) /\left(1+3 \beta x^{2}\right)$ is strictly increasing in $x>0$, so that indeed $\bar{C}_{\beta E} \geq 0$. In addition, $\bar{C}_{L U}=0$, and

$$
\bar{C}_{E U}=-\mu U\left(1+2 \beta U^{2}\right) G^{\prime}(\bar{\varepsilon}) \leq 0 \leq \mu L\left(1+2 \beta L^{2}\right) G^{\prime}(\underline{\varepsilon})=\bar{C}_{E L},
$$

which implies that $\bar{C}$ is submodular in $(E,-L, U,-\beta)$. Consider now

$$
\bar{K}(R ; \beta)=\frac{\lambda \mu \beta}{4} \int_{-\infty}^{\infty} p^{4} d G(\varepsilon),
$$


so that

$$
\bar{K}_{\beta}(R ; \beta)=\frac{\lambda \mu}{4} \int_{-\infty}^{\infty} p^{4} d G(\varepsilon)+\lambda \mu \beta \int_{\underline{\varepsilon}}^{\bar{\varepsilon}} p^{3} p_{\beta} d G(\varepsilon) .
$$

Using Eqs. (26)-(28), it is therefore

$$
\bar{K}_{\beta U}=-\frac{\lambda \mu \beta U^{6} G^{\prime}(\bar{\varepsilon})}{1+3 \beta U^{2}} \leq 0 \leq \lambda \mu \beta L^{6} G^{\prime}\left(\frac{\underline{\varepsilon})}{1+3 \beta L^{2}}=\bar{K}_{\beta L},\right.
$$

and

$$
\bar{K}_{\beta E}=-\lambda\left(\int_{\underline{\varepsilon}}^{\bar{\varepsilon}} \frac{\left(1-3 \beta^{2} p^{4}\right) p^{3}}{\left(1+3 \beta p^{2}\right)^{3}} d G(\varepsilon)+\mu \beta\left(\frac{U^{3} G^{\prime}(\bar{\varepsilon})}{1+3 \beta U^{2}}-L^{3} G^{\prime}\left(\frac{\underline{\varepsilon})}{1+3 \beta L^{2}}\right)\right) \leq 0,\right.
$$

as long as $\beta$ is small. In addition, $\bar{K}_{L U}=\bar{K}_{E L}=\bar{K}_{E U}=0$, so that we have shown that $\bar{K}$ is submodular in $(E,-L, U,-\beta)$. Lastly, consider

$$
\bar{D}(R ; \beta)=\frac{d}{2} \int_{\underline{\varepsilon}}^{\bar{\varepsilon}} E^{2} d G(\varepsilon)+\frac{d}{2} \int_{-\infty}^{\underline{\varepsilon}}\left(e_{0}+\varepsilon-\mu L\left(1+\beta L^{2}\right)\right)^{2} d G(\varepsilon)+\frac{d}{2} \int_{\bar{\varepsilon}}^{\infty}\left(e_{0}+\varepsilon-\mu U\left(1+\beta U^{2}\right)\right)^{2} d G(\varepsilon),
$$

whence

$$
\begin{aligned}
\bar{D}_{\beta}(R ; \beta) & =-\mu d\left[L^{3} \int_{-\infty}^{\underline{\varepsilon}}\left(e_{0}+\varepsilon-\mu L\left(1+\beta L^{2}\right)\right) d G(\varepsilon)+U^{3} \int_{\bar{\varepsilon}}^{\infty}\left(e_{0}+\varepsilon-\mu U\left(1+\beta U^{2}\right)\right) d G(\varepsilon)\right], \\
& =-\mu d\left[L^{3} \int_{-\infty}^{\underline{\varepsilon}}(E+\varepsilon-\underline{\varepsilon}) d G(\varepsilon)+U^{3} \int_{\bar{\varepsilon}}^{\infty}(E+\varepsilon-\bar{\varepsilon}) d G(\varepsilon)\right] .
\end{aligned}
$$

Thus, we find

$$
\begin{aligned}
& \bar{D}_{\beta L}=\mu d(1-G(\underline{\varepsilon})) L^{2}\left[3(E+\mathbb{E}[\tilde{\varepsilon} \mid \tilde{\varepsilon} \leq \underline{\varepsilon}]-\underline{\varepsilon})-\mu L\left(1+3 \beta L^{2}\right)\left(1+E G^{\prime}(\underline{\varepsilon})\right)\right] \geq 0, \\
& \bar{D}_{\beta U}=-\mu d(1-G(\bar{\varepsilon})) U^{2}\left[3(E+\mathbb{E}[\tilde{\varepsilon} \mid \tilde{\varepsilon} \geq \bar{\varepsilon}]-\bar{\varepsilon})-\mu U\left(1+3 \beta U^{2}\right)\left(1+E G^{\prime}(\bar{\varepsilon})\right)\right] \leq 0, \\
& \bar{D}_{\beta E}=\mu d\left[U^{3} G^{\prime}(\bar{\varepsilon})-L^{3} G^{\prime}(\underline{\varepsilon})\right] \geq 0 .
\end{aligned}
$$

Moreover, $\bar{D}_{L U}=0$, and $\bar{D}_{E L}=-d E G^{\prime}(\underline{\varepsilon}) \leq 0 \leq d E G^{\prime}(\bar{\varepsilon})=\bar{D}_{E U}$, which, together with the previous inequalities, implies that $\bar{D}$ is submodular in $(E, L,-U,-\beta)$. Hence, for small damages $\bar{W}$ is supermodular in $(E,-L, U,-\beta)$, and for large damages $\bar{W}$ is supermodular in $(E, L,-U,-\beta)$. First, this implies that $E^{*}(\beta)$ is decreasing. Second, for small environmental damages, $L^{*}(\beta)$ is increasing and $U^{*}(\beta)$ is decreasing (i.e., more stringent price control). Third, for high environmental damages, $L^{*}(\beta)$ is decreasing and $U^{*}(\beta)$ is increasing (i.e., less stringent price control).

\section{References}

[1] C.L. Ballard, J.B. Shoven, J. Whally, General equilibrium computations of the marginal welfare costs of taxes in the United States, Amer. Econ. Rev. 75 (1985) 128-138.

[2] W.J. Baumol, W.E. Oates, The Theory of Environmental Policy, Cambridge University Press, Cambridge, UK, 1988.

[3] A.L. Bovenberg, R.A. de Mooij, Environmental levies and distortionary taxation, Amer. Econ. Rev. 84 (1994) 1085-1089.

[4] C. Carraro, M. Galeotti, M. Gallo, Environmental taxation and unemployment: some evidence on the 'double dividend hypothesis' in Europe, J. Public Econ. 62 (1996) 141-181.

[5] R. Coase, The problem of social cost, J. Law Econ. 30 (1960) 1-44.

[6] T.D. Crocker, The structuring of atmospheric pollution control systems, in: H. Wolozin (Ed.), The Economics of Air Pollution, Norton, New York, NY, 1966, pp. 61-86.

[7] J.H. Dales, Pollution, Property, and Prices, University of Toronto Press, Toronto, Canada, 1968.

[8] V. Denicolò, Pollution-reducing innovations under taxes or permits, Oxford Econ. Pap. 51 (1999) 184-199.

[9] O. Edenhofer, K. Lessman, C. Kemfert, M. Grubb, J. Köhler, Induced technological change: exploring its implications for the economics of atmospheric stabilization, Energy J. 27 (2006) 57-122.

[10] P.-A. Enkvist, T. Nauclér, J. Rosander, A cost curve for greenhouse gas reduction, McKinsey Quart. (February) (2007) $35-45$.

[11] H. Fell, I.A. MacKenzie, W.A. Pizer, Prices versus quantities versus bankable quantities, Resources for the Future, Washington, DC, 2008.

[12] C. Fischer, I.W.H. Parry, W.A. Pizer, Instrument choice for environmental protection when technological innovation is endogenous, J. Environ. Econ. Manage. 45 (2003) 523-545.

[13] L.H. Goulder, K. Mathai, Optimal $\mathrm{CO}_{2}$ abatement in the presence of induced technological change, J. Environ. Econ. Manage. 39 (2000) 1-38.

[14] L.H. Goulder, I.W.H. Parry, Instrument choice in environmental policy, Rev. Environ. Econ. Pol. 2 (2008) $152-174$.

[15] M. Grubb, Technologies, energy systems and the timing of $\mathrm{CO}_{2}$ emissions abatement, Energy Pol. 25 (1997) $159-172$.

[16] M. Grubb, K. Neuhoff, Allocation and competitiveness in the EU emissions trading scheme: policy overview, Climate Pol. 6 (2006) 7-30.

[18] C. Hepburn, M. Grubb, K. Neuhoff, F. Matthes, M. Tse, Auctioning of EU ETS phase II allocations: how and why?, Climate Pol 6 (2006) 135-158.

[19] J. Hicks, The Theory of Wages, Macmillan, London, UK, 1932.

[21] M. Hoel, L. Karp, Taxes versus quotas for a stock pollutant, Resource Energy Econ. 24 (2002) 367-384.

[22] T.W. Hungerford, Algebra, Springer, New York, NY, 1974.

[23] IEA, World Energy Outlook, International Energy Agency, Paris, France, 2008.

[24] IPCC, Climate Change 2007-Mitigation of Climate Change: Working Group III Contribution to the Fourth Assessment Report of the IPCC, Cambridge University Press, Cambridge, UK, 2008. 
[25] C. Jung, K. Krutilla, R. Boyd, Incentives for advanced pollution abatement technology at the industry level: an evaluation of policy alternatives, J. Environ. Econ. Manage. 30 (1996) 95-111.

[26] C. Kennedy, Induced bias in innovation and the theory of distribution, Econ. J. 74 (1964) 541-547.

[27] J.-J. Laffont, More on prices vs. quantities, Rev. Econ. Stud. 44 (1977) 177-182.

[29] A. Löschel, Technological change in economic models of environmental policy: a survey, Ecolog. Econ. 43 (2002) 105-126.

[30] W.J. McKibbin, P.J. Wilcoxen, The role of economics in climate change policy, J. Econ. Perspect. 16 (2002) 107-129.

[31] P.R. Milgrom, J. Roberts, The economics of modern manufacturing: technology, strategy, and organization, Amer. Econ. Rev. 80 (1990) 511-528.

[32] P. Milgrom, C. Shannon, Monotone comparative statics, Econometrica 62 (1994) 157-180.

[33] S.R. Milliman, R. Prince, Firm incentives to promote technological change in pollution control, J. Environ. Econ. Manage. 17 (1989) $247-265$.

[34] F. Missfeldt, J. Hauff, The role of economic instruments, in: A.D. Owen, N. Hanley (Eds.), The Economics of Climate Change, Routledge, New York, NY, 2004, pp. 115-146.

[35] J.-P. Montero, Price versus quantities with incomplete enforcement, J. Public Econ. 85 (2002) 435-454.

[36] W.D. Montgomery, Markets in licenses and efficient pollution control programs, J. Econ. Theory 5 (1972) 395-418.

[37] D.M.G. Newbery, J.E. Stiglitz, The Theory of Commodity Price Stabilization, Clarendon Press, Oxford, UK, 1981.

[39] W.D. Nordhaus, Some skeptical thoughts on the theory of induced innovation, Quart. J. Econ. 87 (1973) 208-219.

[40] W.D. Nordhaus, Economic growth and the climate: the carbon dioxide problem, Amer. Econ. Rev. 67 (1977) 341-346.

[41] W.D. Nordhaus, To tax or not to tax: alternative approaches to slowing global warming, Rev. Environ. Econ. Pol. 1 (2007) 26-44.

[42] I.W.H. Parry, Pollution regulation and the efficiency gains from technological innovation, J. Regul. Econ. 14 (1998) 229-254.

[44] D.W. Pearce, The role of carbon taxes in adjusting to global warming, Econ. J. 101 (1991) 938-948.

[46] C. Philibert, Price Caps and Price Floors in Climate Policy: A Quantitative Assessment, International Energy Agency, Paris, France, 2008.

[47] A.C. Pigou, The Economics of Welfare, Macmillan, New York, NY, 1920.

[48] W.A. Pizer, Combining price and quantity controls to mitigate global climate change, J. Public Econ. 85 (2002) 409-434.

[49] M.J. Roberts, A.M. Spence, Effluent charges and licenses under uncertainty, J. Public Econ. 5 (1976) 193-208.

[50] M. Rothchild, J.E. Stiglitz, Increasing risk: I. A definition, J. Econ. Theory 2 (1971) 225-243.

[51] P.A. Samuelson, A theory of innovation along Kennedy-Wei[z]säcker lines, Rev. Econ. Statist. 47 (1965) 343-356.

[53] R.N. Stavins, Transaction costs and tradable permits, J. Environ. Econ. Manage. 29 (1995) 133-148.

[54] R.N. Stavins, Correlated uncertainty and policy instrument choice, J. Environ. Econ. Manage. 30 (1996) 218-232.

[55] N. Stern, The Economics of Climate Change: The Stern Review, Cambridge University Press, Cambridge, UK, 2007.

[56] B. Strulovici, T.A. Weber, Monotone comparative statics: geometric approach, J. Optimiz. Theory App. 137 (2008) 641-673.

[57] R.S.J. Tol, The damage costs of climate change toward more comprehensive calculations, Environ. Resource Econ. 5 (1995) 353-374.

[58] D.M. Topkis, Ordered optimal solutions, Doctoral Dissertation, Stanford University, Stanford, CA, 1968.

[59] C.C. von Weizsäcker, Tentative notes on a two sector model with induced technical progress, Rev. Econ. Stud. 33 (1966) 245-251.

[60] M.L. Weitzman, Prices vs. quantities, Rev. Econ. Stud. 41 (1974) 477-491.

[61] M.L. Weitzman, Optimal rewards for economic regulation, Amer. Econ. Rev. 68 (1978) 683-691. 